\title{
Interaction of Fusarium solani f. sp. glycines and Heterodera glycines in Sudden Death Syndrome of Soybean
}

\author{
Lijuan Xing and Andreas Westphal
}

Department of Botany and Plant Pathology, Purdue University, West Lafayette, IN 47907.

Accepted for publication 2 March 2006.

\begin{abstract}
Xing, L. J., and Westphal, A. 2006. Interaction of Fusarium solani f. sp. glycines and Heterodera glycines in sudden death syndrome of soybean. Phytopathology 96:763-770.

Sudden death syndrome (SDS) of soybean is caused by the soilborne Fusarium solani f. sp. glycines (synonym $F$. virguliforme). In a sequential approach, two multifactor factorial-design microplot experiments were conducted to investigate the effects of fungal infestation levels and soil moisture on both root necrosis and foliar SDS severity, and the interaction between $F$. solani f. sp. glycines and Heterodera glycines in fumigated versus nonfumigated soil. In 2003, soybean cv. Spencer was grown in nonfumigated or methyl bromide-fumigated soil and infested with increasing levels of $F$. solani f. sp. glycines, either under rainfall or irrigated after growth stage V6/R1. In 2004, interactions between $F$. solani f. sp.

soils without the nematode on the soybean cultivars susceptible to both pathogens. Both natural infestations of $H$. glycines in 2003 and artificially amended populations of $\mathrm{H}$. glycines in 2004 contributed to higher foliar SDS severity. More severe foliar SDS symptoms always were associated with more root necrosis, but elevated levels of root necrosis did not predict severe leaf symptoms. In contrast to the critical role of $H$. glycines, increasing fungal infestation levels had no significant effects on increasing either foliar SDS symptoms or root necrosis. Effects of moisture regime and fungal infestation levels also were examined in factorial greenhouse and growth chamber experiments. High soil moisture resulted in higher levels of SDS root necrosis. In the greenhouse, root necrosis increased at a higher rate in low soil moisture than the rate in high soil moisture. The two pathogens acted as a complex and the disease development was strongly dependent on high soil moisture.
\end{abstract} glycines and $\mathrm{H}$. glycines were explored in a factorial inoculation design in fumigated or nonfumigated soil, planted to Williams 82 or Cyst-X20-18. In both years, higher levels of foliar SDS severity and root necrosis were found in $F$. solani f. sp. glycines-infested soils with $H$. glycines than in
Additional keywords: co-inoculation, disease complex, Glycine max, soybean cyst nematode.
Sudden death syndrome (SDS) is an important disease in most soybean-growing areas of the United States and Canada (50). The soilborne fungus Fusarium solani $\mathrm{f}$. sp. glycines (synonym: $F$. virguliforme) (2) is the causal agent of SDS (30). The pathogen first was identified as $F$. solani "form A" or a blue isolate of $F$. solani in 1989 (32,34). The pathogen infects soybean (Glycine max (L.) Merr.) roots early in the season $(12,19,27)$ and, when high soil moisture is present at the beginning of the reproductive stages of soybean, the pathogen produces toxins that are translocated into aboveground parts of the plant where they cause foliar symptoms (16). In severe cases, SDS results in flower and seed pod abortion, reduced pod and seed fill, premature defoliation, and yield losses (31). The importance of root colonization, discoloration, and necrosis in identifying resistant germplasm, disease development, and the effects of differential infection on the root system have been reported earlier in greenhouse and field studies $(9,19,25$, $27,28,34)$. It is surmised that resistance traits to root rot and SDS foliar symptoms are conferred independently $(9,19,27)$. However, it is not clear how root necrosis relates to foliar symptoms of SDS under field conditions.

Management of SDS has been difficult. Fungicides have not provided effective suppression of SDS, and crop rotation is not always effective and does not provide a reliable management alternative $(12,39)$. Selecting for host-plant resistance has been successful in identifying some resistant cultivars, but introgression remains difficult because resistance relies on several minor

Corresponding author: A. Westphal; E-mail address: westphal@purdue.edu

DOI: 10.1094/PHYTO-96-0763

(C) 2006 The American Phytopathological Society genes (14). In addition, screening for resistance is difficult in the field and greenhouse $(10,23,25)$ because disease onset and expression are strongly dependent on environmental factors $(36,44)$. Information is limited on the potential of biological control of this disease as an alternative, environmentally friendly approach. Only limited tests have been done to evaluate the potential of biological control agents against $F$. solani f. sp. glycines $(4,35$, 42,54). Perhaps most importantly, integrated approaches to management of SDS suffer from the lack of understanding of the ecology of the pathogen and factors that favor development of the disease.

In the Midwest of the United States, SDS tends to be most severe in soybean plants with high yield potential $(11,31,36,40)$ and in soil with high levels of fertility (P, $\mathrm{Mg}$, and organic matter) (40). SDS is favored by high soil moisture levels during the reproductive stages and by unseasonably low temperatures prior to or during flowering and pod set $(31,36,43)$. The disease typically occurs first in low, wet, and compacted areas in a given field and is prevalent in irrigated fields or in areas of the field where the soybean cyst nematode ( $\mathrm{SCN})$, Heterodera glycines, has been a problem (31). F. solani f. sp. glycines alone causes SDS, but SDS often is found in association with H. glycines (31, 32,38). Although neither H. glycines nor other root infections are required for SDS, they all share similar environmental factors for disease development (38). The most severe outbreaks of the disease have been observed in fields that are infested with $H$. glycines $(11,31,40)$. Previous studies on the interaction between $F$. solani $\mathrm{f}$. sp. glycines and $H$. glycines and their effects on SDS development were conducted under both greenhouse and field microplot conditions only in fumigated soil with continuous or periodic irrigation $(20,24,32)$. These experiments were conducted to examine 
fewer factors than those that possibly are involved in progression of foliar symptoms under field conditions. Therefore, further research with factorial investigation of both the abiotic factor (water) and biotic factors ( $F$. solani f. sp. glycines, H. glycines, and other soil microorganisms) in a systematic approach is urgently needed. Such study will determine whether the presence of indigenous microorganisms in the soil alters the relationship between $F$. solani f. sp. glycines and $H$. glycines and SDS development in irrigated or nonirrigated field conditions. Although foliar SDS severity was higher and yields were more suppressed with $H$. glycines infestation than $F$. solani $\mathrm{f}$. sp. glycines infestation alone $(20,21,24,32)$, the correlation between foliar SDS severity and SCN density in soil, and soybean yield, was inconsistent $(11,17,20,40,45)$, and more information is needed to explain the variation in such studies. In summary, the nature of this potential relationship and the putative interaction of both pathogens under field conditions still remain unclear.

Our objectives were to investigate the ecological aspects of $F$. solani f. sp. glycines and to identify the interactions among $F$. solani f. sp. glycines, $H$. glycines, or other soil microorganisms in controlled field microplot environments. In this study, in multifactor factorial design, we tested whether threshold levels of $F$. solani f. sp. glycines can be determined and how $F$. solani $\mathrm{f}$. sp. glycines and $H$. glycines interact in nonfumigated versus preseason-fumigated field soil under simulated field conditions. Determining the effects of these soil treatments on the correlation between foliar SDS severity and external root necrosis was part of this study. In both 2003 and 2004, SDS-susceptible soybean was planted into fumigated and nonfumigated soil amended with inoculum of $F$. solani f. sp. glycines. In 2003, different soil moisture levels and infestation levels of $F$. solani $\mathrm{f}$. sp. glycines in soil were investigated on SDS development and disease severity on soybean cv. Spencer in fumigated or nonfumigated soil. In 2004, potential interactions between $F$. solani f. sp. glycines and $H$. glycines were explored when they were inoculated into plots in a factorial design with fumigated or nonfumigated soil. The disease response of the $H$. glycines-resistant soybean line Cyst-X2018 (U.S. patent \#6,096,944) was compared with the SDS- and SCN-susceptible soybean cv. Williams 82. A greenhouse assay was developed to determine effects of inoculum levels of $F$. solani f. sp. glycines and to investigate the role of soil moisture on root rot severity. Preliminary results were reported previously (51-53).

\section{MATERIALS AND METHODS}

Production of $\boldsymbol{F}$. solani f. sp. glycines and $\boldsymbol{H}$. glycines inoculum. Two isolates of $F$. solani f. sp. glycines (Francesville and Lafayette) were used in this study, both isolated from diseased soybean roots in fields naturally infested with $F$. solani f. sp. glycines (Scott Abney, United States Department of AgricultureAgricultural Research Service, Purdue University). The isolates were stored in $50 \%$ glycerol solution at $-80^{\circ} \mathrm{C}$. Active cultures were obtained on potato dextrose agar (PDA) by incubation for 2 to 3 weeks at $22 \pm 3^{\circ} \mathrm{C}$. Each isolate was grown separately on sterile sand-cornmeal medium (SC) (1 liter of sand, $56 \mathrm{ml}$ of food-grade cornmeal, and $325 \mathrm{ml}$ of $\mathrm{H}_{2} \mathrm{O}$ ) for 1 month in glass mason jars at $22 \pm 3^{\circ} \mathrm{C}$.

Populations of $H$. glycines were grown on soybean (cv. Lee 74) inoculated with second-stage juveniles in pots with autoclaved sand:soil mixture $(2: 1, \mathrm{vol} / \mathrm{vol})$ (SS) under greenhouse conditions with a 12-h photoperiod of fluorescent light at $25 \pm 2{ }^{\circ} \mathrm{C}$ for 3 months. At the same time, non-nematode-inoculated pots were prepared for controls. After incubation, roots and plant debris were removed, and the SS was dried for 2 weeks under paper to avoid direct sun exposure. Such SS with or without cysts of H. glycines was sieved (8-mm aperture sieve) and used as nematode inoculum or control treatment.
Field microplots. The microplot tests of 2003 and 2004 were conducted in $45-\mathrm{cm}$-diameter, corrugated polyethylene drainage tubing with a smooth inside surface, inserted perpendicularly $55 \mathrm{~cm}$ deep into the ground at the Agronomy Center for Research and Education, Purdue University, West Lafayette, IN. In both years, the multifactor factorial experiments were arranged in randomized complete block designs with four replications. Methyl bromide was applied through a dry-connect system at a $25-\mathrm{cm}$ depth. Plots were covered immediately with $0.1-\mathrm{mm}$ thick, black polyethylene sheets and sealed. After incubation for 6 days, the plots were aerated sufficiently before the other factors were applied.

In spring 2003, soil (22\% sand, $56 \%$ silt, $22 \%$ clay, $\mathrm{pH} 7$ ) from a field naturally infested with $H$. glycines was mixed and placed in the plots. In a three-factor factorial design, the following treatments were applied: (i) nonfumigated or methyl bromidefumigated at $450 \mathrm{~kg} / \mathrm{ha}$; (ii) natural precipitation or 15 liters of water added once per week after R1 (8); and (iii) four F. solani $\mathrm{f}$. sp. glycines infestation levels. The SC inocula of the two F. solani f. sp. glycines isolates were mixed with autoclaved, previously infested SC to establish an infestation series of $0,6.3 \times 10^{3}, 3.2 \times$ $10^{4}$, or $1.7 \times 10^{5}$ macrospores $/ \mathrm{ml}$ of soil by amending $400 \mathrm{~g}$ of such mixes to each plot and incorporating into the top $15 \mathrm{~cm}$ of soil, because the pathogen was shown to be most frequent in this depth layer in naturally occurring SDS fields (38). Noninfested plots received autoclaved, previously infested SC in the same way. Soybean cv. Spencer (susceptible to both $F$. solani f. sp. glycines and $H$. glycines) was planted on 6 May 2003 and thinned to 20 plants per plot in three parallel rows at $12.5-\mathrm{cm}$ spacing after emergence.

In spring 2004, field-derived soil without a documented history of SDS (52\% sand, $30 \%$ silt, $18 \%$ clay, $\mathrm{pH} 6.9$ ) was mechanically broken with a soil shredder (Model 112; Royer Foundry and Machine Co., Kingston, PA), mixed, and placed in the plots. The following treatments were applied in a four-factor factorial design: (i) nonfumigated or methyl bromide-fumigated at $450 \mathrm{~kg} / \mathrm{ha}$; (ii) noninoculated or inoculated with $400 \mathrm{~g}$ of $F$. solani f. sp. glycines $\mathrm{SC}$ inoculum resulting in a rate of $3.9 \times 10^{5}$ macrospores $/ \mathrm{ml}$ of soil; (iii) noninfested or infested with $400 \mathrm{~g}$ of $\mathrm{H}$. glycines inoculum, adding $9.4 \times 10^{4}$ eggs in 1,207 cysts per plot, resulting in 390 eggs per $100 \mathrm{ml}$ of soil and 5 cysts per $100 \mathrm{ml}$ of soil; and (iv) planted to Williams 82 (susceptible to both $F$. solani f. sp. glycines and $H$. glycines) or Cyst-X20-18 (resistant to $H$. glycines but with unknown resistance status to $F$. solani f. sp. glycines). Williams 82 was chosen because it is one of the parents of the original cross to generate Cyst-X20-18 (7). The SC inocula of the two $F$. solani f. sp. glycines isolates or the SS with or without cysts of $H$. glycines were mixed into the upper $15 \mathrm{~cm}$ of soil on 12 May 2004. Autoclaved, previously infested SC was applied in the same way to the proper treatments; noninfested greenhouseculture soil was amended to non- $H$. glycines-infested treatments. Soybean cvs. Williams 82 or Cyst-X20-18 were planted in three parallel rows at $12.5-\mathrm{cm}$ spacing on 15 May 2004 and thinned to 20 plants per plot after emergence.

In both years, beginning at the V6/R1 growth stage of soybean, the appropriate plots (in 2003) or all plots (in 2004) received 15 liters of water once or twice per week to keep soil moisture levels $\leq 50$ mbar as determined with tensiometers in two randomly chosen plots. All plots were monitored for SDS occurrence. Disease reactions were assessed by the severity of SDS foliar symptoms. Population densities of $H$. glycines were determined by taking soil samples from the plots before fumigation in 2003, at planting in 2004, and after harvest in both years. Populations of $H$. glycines were extracted by elutriation (3) and the cysts were counted. Cysts were crushed with a modified cyst crusher (6) and then eggs were counted. At R6 on 29 August 2003, R5-R6 on 3 September 2004, foliar SDS severity was rated on a scale of 0 to 9 (19). Percent defoliation was rated on 19 September 2003 and 
on 13, 17, 22, and 25 September 2004. On 19 September 2003 (R6) and 22 September 2004 (R6 to R8), soybean plants of the two side rows in each plot were removed for assessment of external root necrosis (Table 1) and presence of Diaporthe stem rot was recorded. The middle row was harvested for seed yield on 15 October 2003 and 12 October 2004, respectively. Yields were converted to $13 \%$ moisture before analysis.

Greenhouse and growth chamber experiments. F. solani $\mathrm{f}$. sp. glycines inoculum (Francesville isolate) raised in SC was used in this assay. After 1 month's growth, fungal inocula were mixed with SS to obtain five serial infestation levels of $0.08,0.4,2,10$, and $50 \%$ (vol/vol). Final macrospore density per milliliter of potting soil was adjusted to increase exponentially at $11,700 \times 5^{\mathrm{I}}$, where the exponent $\mathrm{I}=0$ to 4 (equivalent to $1.2 \times 10^{4}$ to $7.3 \times$ $10^{6}$ ). Inoculum-SS mixtures were placed in $120-\mathrm{ml}$ plastic cones (Stuewe \& Sons, Inc., Corvallis, OR) in modification of the method described by Gray and Achenbach (9). A nonamended SS (C1) and a mix of autoclaved SC inoculum and SS (1:1, vol/vol) (C2) were controls. Soybean cv. Williams 82 was grown in the cones in a three-factor factorial experiment. Factors were (i) five infestation levels; (ii) watered from the bottom (cone tip submerged $5 \mathrm{~cm}$ deep into a $150-\mathrm{cm}^{3}$ water-filled plastic cup) or watered from the top; and (iii) planted to 10-day-old seedlings or direct-seeded. The experiments were arranged in randomized complete block designs with four replications and conducted twice for each of the following environments: (i) in a heated greenhouse at $25 \pm 3^{\circ} \mathrm{C}, 16$-h day and 8-h night cycle; or (ii) in an environmental growth chamber at the same temperature and day-night cycle, with $70 \%$ relative humidity and light intensity of $300 \mu \mathrm{mol} / \mathrm{m}^{2} / \mathrm{s}$. During the growth period, each cone received $30 \mathrm{ml}$ of nutrient solution $(15 \% \mathrm{~N}, 13 \% \mathrm{P}, 12 \% \mathrm{~K}$, and various micronutrients) once per week via a commercial fertilizer at label rates (Miracle Gro; Scotts Miracle-Gro Products Inc., Marysville, $\mathrm{OH}$ ). After 8 weeks, soybean plants were harvested, roots washed free of soil, and root dry weights determined. The percentage of root necrosis was estimated visually on a scale of 0 to $100 \%$.

Data analysis. Analysis of variance (ANOVA) was conducted with the general linear model (GLM) in SAS (SAS Institute, Cary, NC). The microplot data were entered into a randomized complete block design after testing for homogeneity of error variances. Data were transformed before entering into ANOVA: top rating, arcsine (square root of [top rating/9]); root rating, arcsine (square root of [root rate/5]); and nematode numbers, $\log _{10}(x+1)$. The appropriate least significant differences were generated at $P=0.05$ and 0.10 to compare the treatments. In the greenhouse and growth chamber experiments, data were transformed prior to ANOVA: root necrosis, arcsine (square root of [percent root necrosis/100]); and root dry weights, square root of root dry weight. When ANOVA error variances were homogeneous, experiments were combined. For the root necrosis, inoculum effects and interactions of the factors were partitioned into orthogonal polynomial contrasts. Each control was compared with the five individual inoculum levels by $t$ tests $(P=0.05)$ within each environment, each plant stage at planting, and each watering method. Regression models were developed for significant inoculum effects.

\section{RESULTS}

Field microplots. In 2003, SDS foliar symptoms were most severe in the irrigated/nonfumigated soil, less in the nonirrigated/ nonfumigated soil, limited in the irrigated/fumigated soil, and barely detectable in the nonirrigated/fumigated soil $(P \leq 0.05)$ (Fig. 1A). The progression of defoliation followed a pattern similar to the SDS foliar symptoms (Table 2). Although, in spring before fumigation, the nonfumigated plots had medium egg population densities of $H$. glycines (400 eggs/100 g of soil), the soybean plants under natural rainfall supported higher egg and
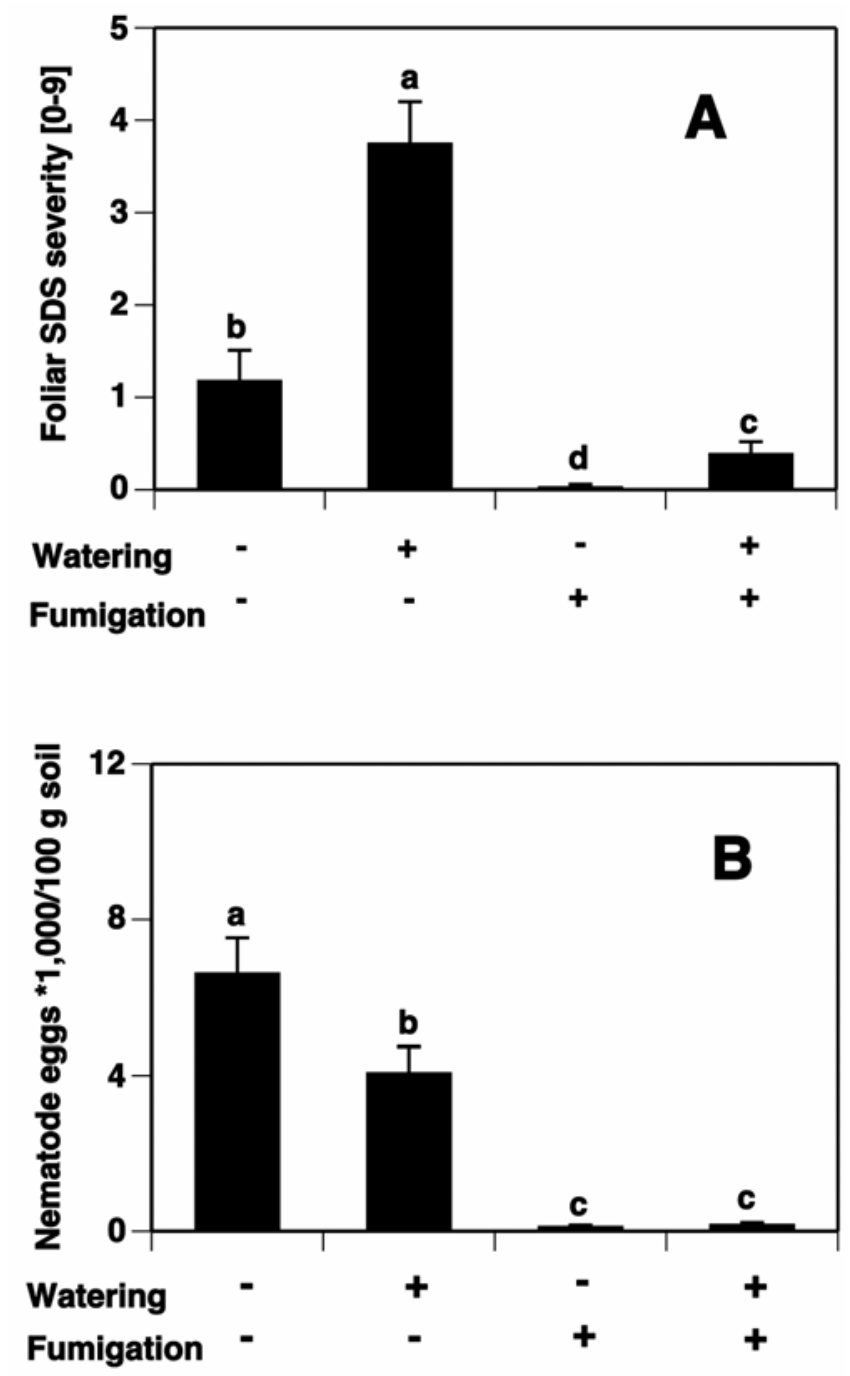

Fig. 1. Effects of soil treatments on foliar sudden death syndrome (SDS) severity and population density of Heterodera glycines in microplots in 2003; original means are shown; analysis of variance was conducted on transformed data. A, Foliar SDS severity at R6 (scale: 0 to 9) (arcsine [square root of (top rating/9)]). B, Population densities of $H$. glycines at harvest, $\left(\log _{10}[x+1]\right)$. Bars with the same letter are not significantly different at $P=0.05$; (-) factors not applied and (+) factors applied.

TABLE 1. External root necrosis rating scheme for soybean in microplots during 2003 and 2004

\begin{tabular}{|c|c|c|}
\hline Rating & 2003 & 2004 \\
\hline 0 & Tap root healthy, no necrosis, copious secondary and fibrous roots & $\ldots$ \\
\hline 1 & Some necrosis on tap root, copious secondary and fibrous roots & Tap root healthy, no necrosis, copious secondary and fibrous roots \\
\hline 2 & Tap root with more necrosis and somewhat reduced secondary roots & Healthy tap root, $<50 \%$ necrotic fibrous and secondary roots \\
\hline 3 & Tap root with necrosis, reduced number of fibrous and secondary roots & $\begin{array}{l}\text { Healthy tap root, }>50 \% \text { fibrous roots lost or necrotic, necrosis on } \\
\text { secondary roots }\end{array}$ \\
\hline 4 & Fibrous roots only on the top of the intact tap root, secondary roots necrotic & $<50 \%$ necrotic tap root, no healthy fibrous or secondary roots \\
\hline 5 & Severely necrotic tap root, sometimes tap root broken & $>50 \%$ necrotic tap roots, no healthy fibrous or secondary roots \\
\hline
\end{tabular}


cyst population densities of $H$. glycines (6,643 eggs/100 g of soil) than those under irrigation (4,094 eggs/100 $\mathrm{g}$ of soil) at harvest $(P \leq 0.05)$ (Fig. 1B; Table 2). All these nonfumigated plots with high population densities of $H$. glycines had high levels of foliar SDS severity at harvest (Fig. 1A and B). On average, external root necrosis was higher in the nonfumigated plots compared with preseason-fumigated plots and in irrigated compared with nonirrigated, but the interaction of these two factors was not significant (Table 2). Effects of the infestation levels of the fungal pathogen were not significant (data not shown). Treatments that resulted in increased foliar SDS severity also resulted in increased incidence of Diaporthe stem rot but no correlation between Diaporthe stem rot and SDS was detected (data not shown).

In 2004, SDS foliar symptoms first were observed in the fumigated plots planted to Williams 82 inoculated with both $F$. solani f. sp. glycines and $H$. glycines (data not shown). Six days later, SDS foliar symptoms began to develop in the nonfumigated plots planted to Williams 82 infested with both pathogens, but SDS severity in the nonfumigated plots developed faster than in the fumigated plots. Thereafter, the plants in other treatments, including some plots inoculated only with $H$. glycines cysts, began to show traces of SDS foliar symptoms. In the combined analysis of nonfumigated and preseason-fumigated soil, co-inoculation with both pathogens consistently resulted in the most severe SDS foliar symptoms in Williams 82; only traces of SDS foliar symptoms (not significantly different from 0) were observed in CystX20-18 ( $P \leq 0.01$ ) (Fig. 2). At harvest, cyst and egg population densities under Williams 82 were higher after inoculation with $H$. glycines than in noninoculated soil in both nonfumigated and fumigated soil (Fig. 3; Table 3); egg population densities under Cyst-X20-18 were significantly increased after inoculation compared with the noninoculated treatment in the fumigated soil only (Fig. 3). Egg population densities were higher in each soil treatment with Williams 82 than with Cyst-X20-18, with the exception of the fumigated and noninfested treatment, in which almost no eggs were detected under both cultivars (Fig. 3). External root necrosis was increased in the presence of $H$. glycines on Williams 82 but not on Cyst-X20-18 (Table 3). Seed yields were reduced in $H$. glycines-infested treatment with Williams 82 but not with Cyst-X20-18 (Table 3). On average, defoliation of both cultivars increased beginning at the second monitoring time (from 23 to 33, 56, and 91\%). Defoliation was highest and occurred earliest in

TABLE 2. Effects of soil fumigation and watering regimes on sudden death syndrome in microplots in $2003^{\mathrm{v}}$

\begin{tabular}{|c|c|c|c|c|c|}
\hline \multicolumn{6}{|l|}{ Treatment $^{\mathrm{w}}$} \\
\hline Watering & Fumigation & Defoliation $(\%)^{\mathrm{x}}$ & External root necrosis $(0-5)^{\mathrm{y}}$ & Cysts per $100 \mathrm{~g}$ of soil ${ }^{\mathrm{z}}$ & Seed yield (g/plot) \\
\hline- & - & $62 \pm 5 b$ & $3.5 \pm 0.9$ & $63 \pm 7 a$ & $309 \pm 12$ \\
\hline+ & - & $83 \pm 5 a$ & $4.1 \pm 1.0$ & $47 \pm 6 b$ & $312 \pm 15$ \\
\hline- & + & $13 \pm 4 c$ & $1.2 \pm 0.3$ & $1 \pm 0 \mathrm{c}$ & $310 \pm 15$ \\
\hline+ & + & $18 \pm 5 c$ & $1.3 \pm 0.3$ & $1 \pm 0 \mathrm{c}$ & $345 \pm 25$ \\
\hline \multicolumn{6}{|l|}{$P$ for } \\
\hline Watering & $\ldots$ & $<0.01$ & $<0.01$ & ns & ns \\
\hline Fumigation & $\ldots$ & $<0.01$ & 0.0295 & $<0.01$ & ns \\
\hline Watering $\times$ fumigation & $\ldots$ & 0.0512 & ns & 0.0383 & ns \\
\hline
\end{tabular}

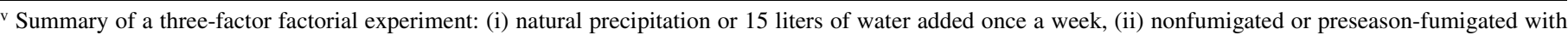
methyl bromide at $450 \mathrm{~kg} / \mathrm{ha}$, and (iii) inoculated with two isolates of Fusarium solani f. sp. glycines at $0,6.3 \times 10^{3}, 3.2 \times 10^{4}$, or $1.7 \times 10^{5}$ macrospores/ml of infestation soil. Means across inoculum levels were not presented because such effects were mostly nonsignificant. Numbers followed by the same letter within one column were not significantly different at $P=0.05$ when the watering $\times$ fumigation effects were significant; $\mathrm{ns}=$ nonsignificant.

w Treatments were not applied (-) or applied (+).

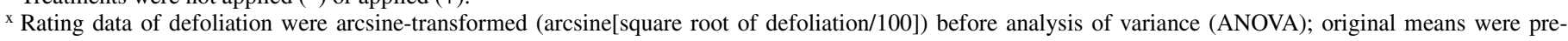
sented; although there were significant infestation level effects $(P=0.0426)$, these were not presented because there were no consistent trends associated with infestation levels.

${ }^{y}$ Rating data of external root necrosis were arcsine-transformed (arcsine[square root of root rating/5]) before ANOVA; original means were presented.

${ }^{z}$ Nematode cyst numbers at harvest were log-transformed $\left(\log _{10}[x+1]\right)$ before ANOVA; original means were presented.

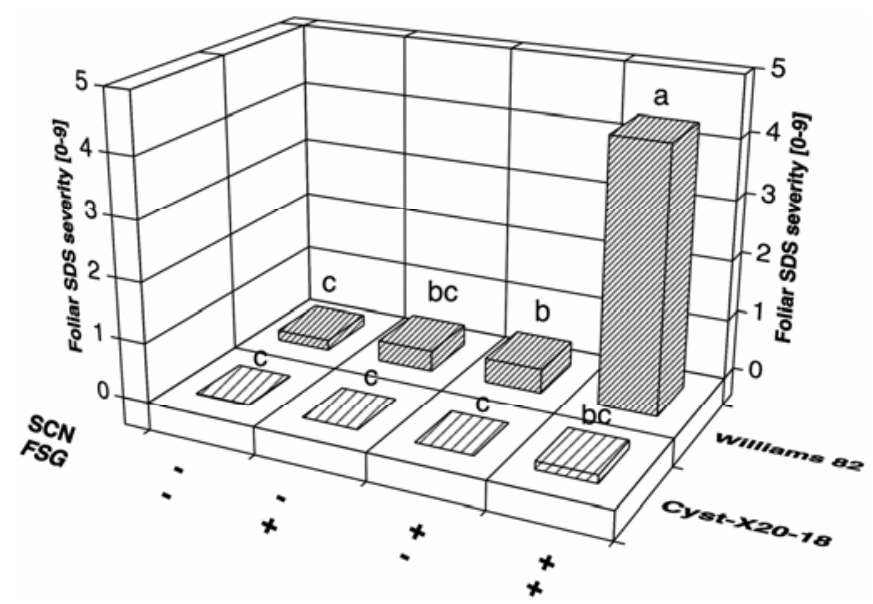

Fig. 2. Effects of inoculation with Heterodera glycines and Fusarium solani f. sp. glycines on severity of sudden death syndrome (SDS) foliar symptoms on Williams 82 and Cyst-X20-18 in microplots on 3 September 2004. Original means are presented. Mean separation of the arcsine-transformed data for cultivar $\times H$. glycines $\times F$. solani $\mathrm{f}$. sp. glycines, averaged across fumigation treatments, is significant at $P \leq 0.01$. Bars with the same letter are not significantly different at $P=0.05$; (-) factors not applied and (+) factors applied; $\mathrm{SCN}=H$. glycines $; F S G=F$. solani $\mathrm{f}$. sp. glycines

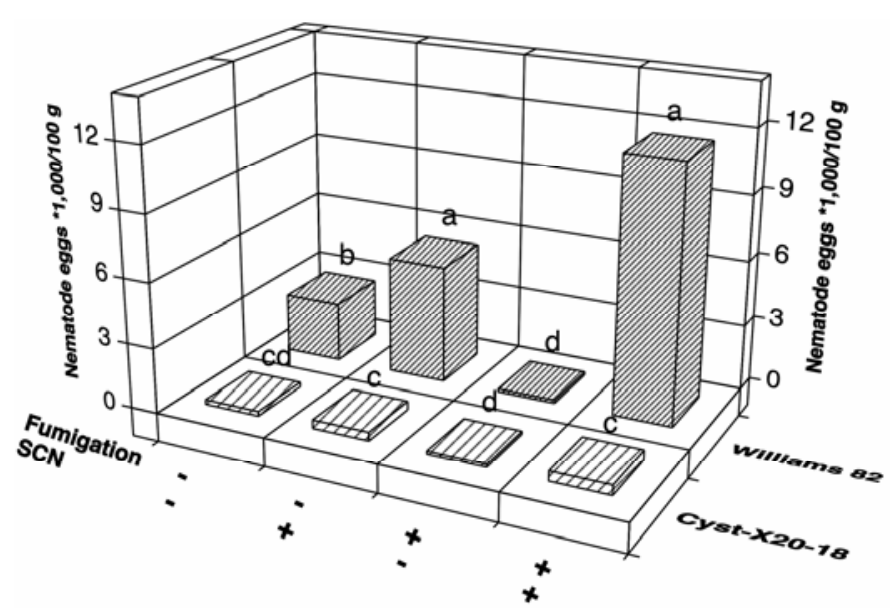

Fig. 3. Soil population densities of Heterodera glycines in Fusarium solani f. sp. glycines-infested microplots under Williams 82 and Cyst-X20-18 after harvest in 2004. Original means are presented. Mean separation of the logtransformed data for cultivar $\times$ fumigation $\times H$. glycines, averaged across $F$. solani f. sp. glycines infestation, are significant at $P \leq 0.05$. Bars with the same letter are not significantly different at $P=0.05$; $(-)$ factors not applied and (+) factors applied; $\mathrm{SCN}=H$. glycines. 
Williams 82 co-inoculated with $F$. solani f. sp. glycines and $H$. glycines compared with all other treatments at each evaluation (Fig. 4A and B). In Williams 82, treatments that included at least one pathogen defoliated more slowly than the co-inoculated treatments, but faster than the noninoculated plots (Fig. 4A). In contrast, the patterns of defoliation in Cyst-X20-18 were more similar among infestation treatments (Fig. 4B). In 2003, relationship between foliar SDS severity and external root necrosis appeared grouped independent of infestation levels, but grouped according to fumigation and irrigation treatments: highest root necrosis ratings and foliar SDS severity in irrigated, nonfumigated plots; second-highest root necrosis ratings and medium foliar SDS severity in nonirrigated and nonfumigated plots; and lower root necrosis ratings and only traces of foliar SDS symptoms in fumigated soil, independent of irrigation treatment (Fig. 5A). In 2004, only co-inoculated plots had high foliar SDS severity together with severe root necrosis. Most other treatments had low levels of foliar SDS severity, although severity of root necrosis varied from low to high levels. Although Cyst-X20-18 in the plots with infestation of both pathogens developed high levels of external root necrosis, it did not develop high levels of foliar SDS severity (Fig. 5B). In Williams 82, different levels of root necrosis existed but only the co-inoculated treatment had severe foliar SDS symptoms; in Cyst-X20-18, only traces of foliar SDS symptoms were detected in the co-inoculated treatment in nonfumigated soil, although varying levels of root necrosis similar to those in Williams 82 were observed (Fig. 5B).

Greenhouse and growth chamber experiments. In both environments, arcsine root necrosis (RN) was greater in infested soil than in the controls; RN was more severe when cone tips were submerged in cups filled with water than when they were watered from the top (Fig. 6A and B). In all tests, roots were more necrotic when inoculum levels increased exponentially $(11,700 \times$ $5^{\mathrm{I}}$, where exponent $\mathrm{I}=0$ to 4 ); the greatest incremental increase in $\mathrm{RN}$ was in the top-watered greenhouse condition (Fig. 6B). A significant correlation between infestation levels and $\mathrm{RN}$ was observed in both environments after the combined regression analysis $\left(R^{2}=0.9944\right.$ at $P<0.0001$ in the growth chamber experiments and $R^{2}=0.9180$ at $P=0.0123$ in the greenhouse experiments). The square root of root dry weight (DW) of soybean was affected by the soybean growth stage at planting (seed or transplant), watering method, and inoculum densities (data not shown).

Although significant differences in root DWs were limited among the inoculation treatments, regression relationships between the root DWs and infestation levels were detected. In the growth chamber, the DW of the infested, direct-seeded soybean plants showed no response to varying inoculum levels, but the transplants had a strong negative response to inoculum levels $(\mathrm{DW}=46.98-2.48 \mathrm{I}$; data not shown). In the greenhouse, increasing inoculum levels resulted in reduced root DW $(\mathrm{DW}=$ $34.55-2.11 \mathrm{I}$ ), with the top-watered transplants having the greatest overall root DW (data not shown). However, the slopes were similar between the growth chamber-infested transplants and all of the greenhouse-infested soybean $(-2.48$ and -2.11 , respectively; data not shown).

\section{DISCUSSION}

In this study, both root necrosis and foliar SDS severity in F. solani f. sp. glycines-infested soil were greatly increased by the

TABLE 3. Effects of cultivar and Heterodera glycines infestation on sudden death syndrome in microplots in 2004×

\begin{tabular}{|c|c|c|c|c|}
\hline Cultivar & H. glycines & External root necrosis $(1-5)^{\mathrm{y}}$ & Cysts per $100 \mathrm{~g}$ of soil ${ }^{\mathrm{z}}$ & Seed yield (g/plot) \\
\hline Williams 82 & - & $2.9 \pm 0.3 b$ & $9.4 \pm 5.4 b$ & $109 \pm 8 \mathrm{a}$ \\
\hline Williams 82 & + & $4.0 \pm 0.2 \mathrm{a}$ & $68.0 \pm 0.1 \mathrm{a}$ & $71 \pm 7 b$ \\
\hline Cyst-X20-18 & - & $3.0 \pm 0.2 \mathrm{~b}$ & $0.3 \pm 6.9 \mathrm{~d}$ & $95 \pm 7 \mathrm{a}$ \\
\hline Cyst-X20-18 & + & $3.3 \pm 0.3 b$ & $4.7 \pm 0.6 \mathrm{c}$ & $102 \pm 10 \mathrm{a}$ \\
\hline \multicolumn{5}{|l|}{$P$ for } \\
\hline Cultivar & $\ldots$ & $<0.01$ & $<0.01$ & ns \\
\hline H. glycines & $\ldots$ & $<0.01$ & $<0.01$ & $<0.01$ \\
\hline Cultivar $\times H$. glycines & $\ldots$ & $<0.01$ & $<0.01$ & $<0.01$ \\
\hline
\end{tabular}

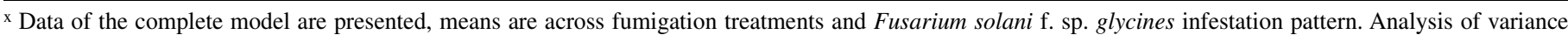
(ANOVA) was done for the appropriately transformed data. Numbers followed by the same letter within each column were not significantly different when tested for cultivar $\times H$. glycines at $P=0.05$; ns = nonsignificant.

y Data were arcsine transformed before ANOVA and mean separation test.

${ }^{\mathrm{z}}$ Nematode population density data at harvest were $\log$-transformed $\left(\log _{10}[x+1]\right)$ before ANOVA and mean separation test.
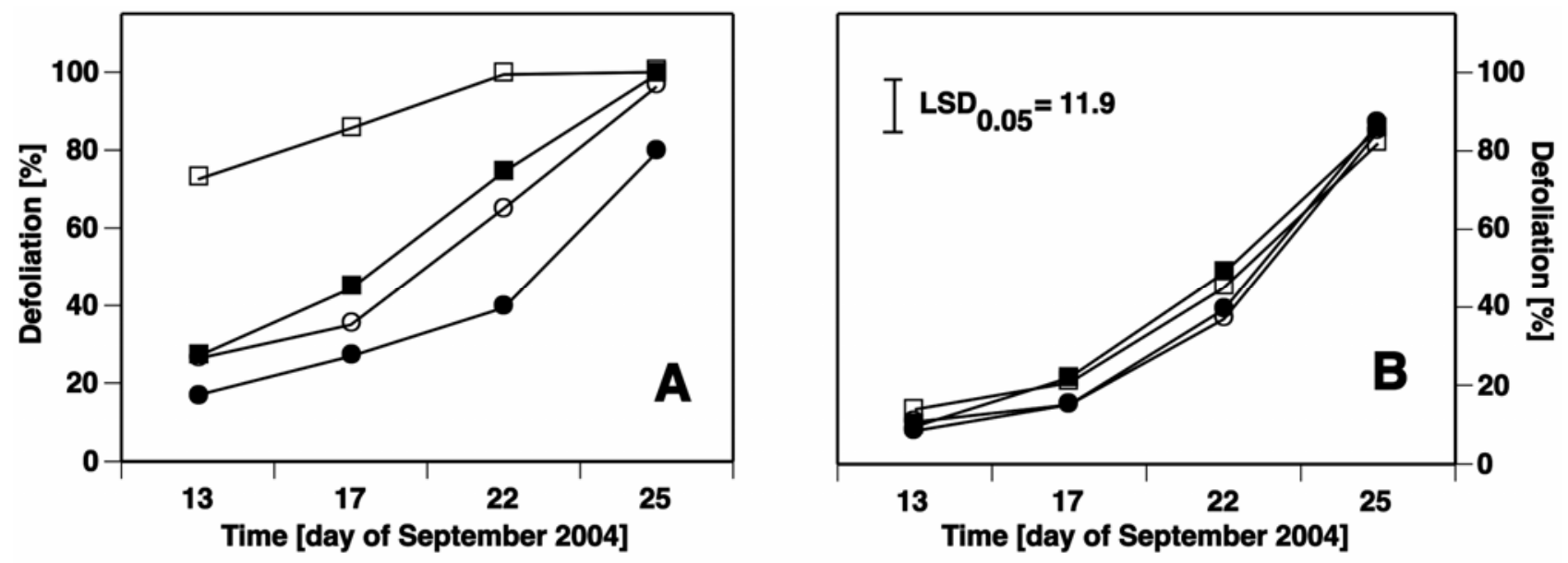

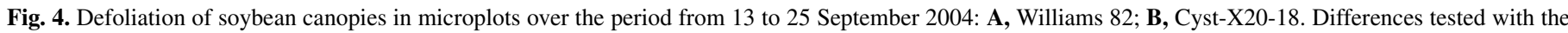

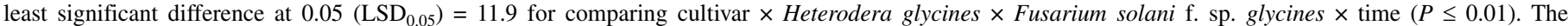

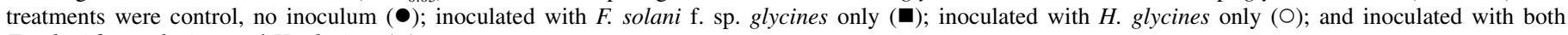
F. solani f. sp. glycines and $H$. glycines $(\square)$. 
presence of $H$. glycines. The correlation between $F$. solani f. sp. glycines and $H$. glycines was evident from two different perspectives. In both years, independent of the source of $H$. glycinesnatural infestation or artificial inoculation - the nematode was the key factor for increased foliar SDS severity. The fungal pathogen and $H$. glycines damaged the plant synergistically, resulting in severe SDS. In 2003, plots with natural populations of $H$. glycines had high levels of SDS, indicating the important role of the nematode in increasing SDS. In 2004, only plots planted to Williams 82 that were co-inoculated with $H$. glycines and $F$. solani f. sp. glycines developed severe foliar SDS symptoms. Documentation of $H$. glycines population densities is indicated when comparing experiments conducted in fields with infestations of both pathogens. Our observation under field conditions further confirmed previous reports $(11,20,24,32,36)$ of a positive correlation between severity of SDS foliar symptoms and populations of $H$. glycines in $H$. glycines-susceptible soybean cultivars. The presence of $H$. glycines hastened and intensified the development and severity of foliar symptoms of SDS in greenhouse or field microplot tests $(18,20,21,24,32)$. In one such test, foliar symptoms of SDSdiseased soybean plants inoculated with both $F$. solani f. sp.
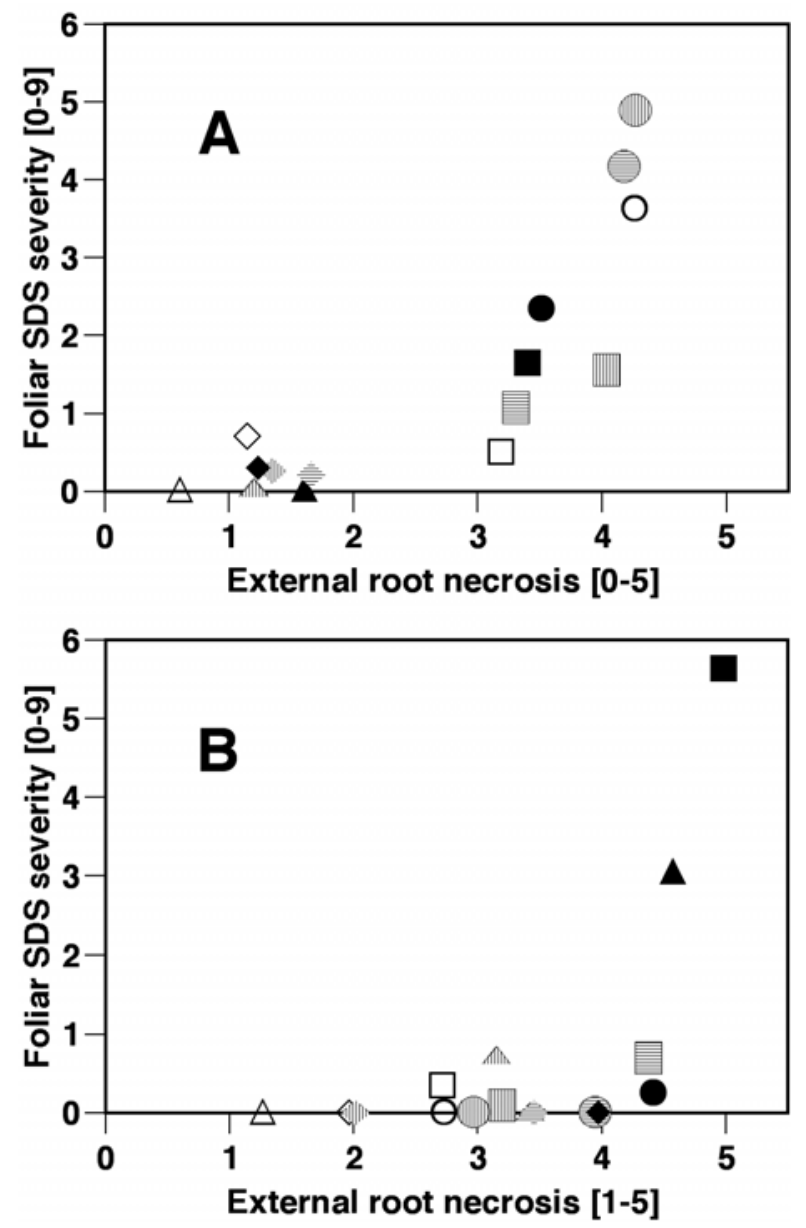

Fig. 5. Scattergram of foliar sudden death syndrome (SDS) severity over external root necrosis of soybean: A, In 2003, each of the four infestation levels in soil was indicated the following ways: fumigated and nonirrigated $(\Delta)$; fumigated and watered $(\diamond)$; nonfumigated and nonirrigated $(\square)$; and nonfumigated and irrigated $(O)$; symbol fills: hollow = no infestation; cross hatch $=$ lowest level of inoculum; vertical hatch $=$ second-highest level of inoculum; and filled = highest level of inoculum of Fusarium solani f. sp. glycines. B, In 2004, soybean cultivars at the four infestation patterns were: Cyst-X20-18 in fumigated soil $(\diamond)$; Cyst-X20-18 in nonfumigated soil $(O)$; Williams 82 in fumigated soil $(\Delta)$; and Williams 82 in nonfumigated soil $(\square)$; symbol fills: hollow $=$ no infestation, cross hatch $=$ inoculated with $F$. solani $\mathrm{f}$. sp. glycines; vertical hatch $=$ inoculated with Heterodera glycines; and filled $=$ inoculated with both $H$. glycines and $F$. solani f. sp. glycines. glycines and $H$. glycines occurred 3 or 9 days earlier than those caused by $F$. solani f. sp. glycines alone (20). The relationship between $F$. solani f. sp. glycines and $H$. glycines is crucially important, particularly in the Midwest, where $H$. glycines was present in 47 to $83 \%$ of the fields surveyed from 1995 to 1996 (49). Similar disease complexes are known for several plant pathogens when nematodes modify the rhizosphere in concomitant infection with soilborne fungi (13). For example, $H$. glycines damages soybean plants synergistically with $F$. oxysporum in Fusarium wilt (29) or in combination with Phytophthora megasperma var. sojae (1).

The second critical factor for SDS development in this study was soil moisture. In microplots, plants grown in the irrigated plots exhibited more severe foliar SDS symptoms than those in the nonirrigated plots. Higher soil moisture treatments also always were associated with higher levels of root necrosis in experiments in the greenhouse and growth chamber. Such interrelation had been found previously for severity of foliar SDS symptoms $(24,32,43)$, which increased with increasing soil moisture in controlled growth chamber and field conditions; however, in those studies, such effects were not related to root
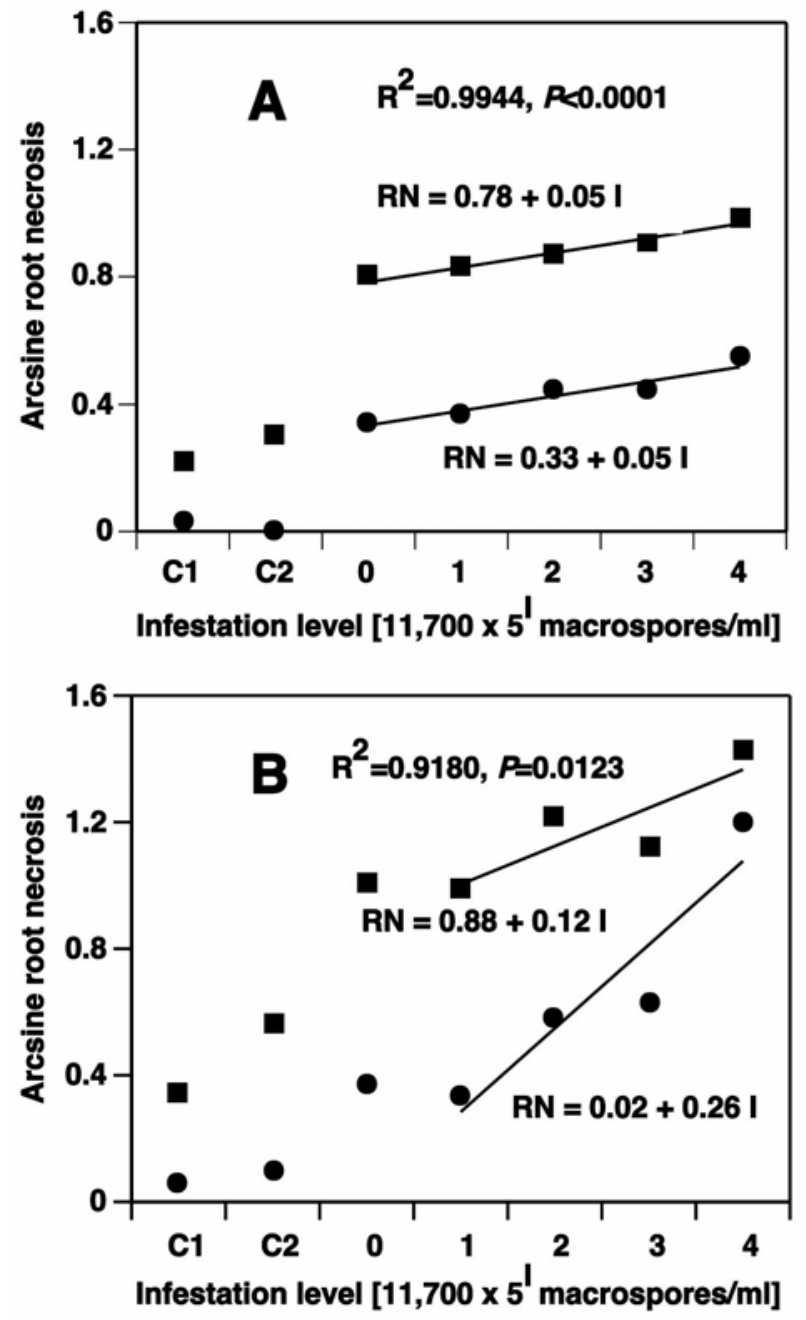

Fig. 6. Root necrosis (RN): arcsine (square root of [percent necrosis/100]) on soybean cv. Williams 82 in plastic cones filled with sand:soil mix infested with increasing levels of Fusarium solani f. sp. glycines expressed as 11,700 $\times$ $5^{\mathrm{I}}$, where the exponent $\mathrm{I}=0$ to 4 , with two controls: $\mathrm{C} 1$ (noninoculated mixture of autoclaved sand:soil $[2: 1, \mathrm{vol} / \mathrm{vol}])$ and $\mathrm{C} 2(\mathrm{mix}[1: 1, \mathrm{vol} / \mathrm{vol}]$ of autoclaved sand:soil mixture and autoclaved spent sand-cornmeal media). A, Growth chamber; for infestation level, the mutual regression was $R^{2}=0.9944$ at $P<0.0001$. B, Greenhouse; for infestation level, the mutual regression was $R^{2}=0.9180$ at $P=0.0123$. The treatments were top watered $(\bullet)$ and cone tip submerged in water-filled cup (ם). 
necrosis of SDS-diseased soybean under greenhouse and field conditions.

SDS onset was accelerated by $H$. glycines in nonfumigated and fumigated plots, resulting in earlier and more severe foliar SDS symptoms than in other plots. Similar observations were made under natural or controlled field conditions $(11,20,24,40,45)$. In 2004, SDS foliar symptoms developed earlier in the fumigated plots than in the nonfumigated plots with infestation of both $F$. solani $\mathrm{f}$. sp. glycines and $H$. glycines. The natural microflora in the otherwise equivalent nonfumigated soil may have delayed disease onset at the aboveground level. However, the epidemics of foliar SDS symptoms developed faster in the nonfumigated soil compared with the fumigated soil, possibly because a number of other soil-inhabiting fungi and oomycetes were impacting the root health of soybean in addition to the inoculum amendments. This potentially complex interactive system may explain the common complication in SDS research: "the disease may be present in a given field one year and be totally absent or too mild in one or more succeeding years to allow for screening" (23). Although this sporadic disease occurrence probably is due to many factors, the interaction of the nematode and the fungus may be a contributing factor. Possibly, this interaction has more dimensions than promotion of SDS; there seems to be a detriment to the nematode in this interaction because severe SDS resulted in lower $H$. glycines population densities than mild SDS, as reported previously (22, $40,45)$ and in this study. In 2003, pathogen populations in soils were in two known groups: group 1, amendment of $F$. solani f. sp. glycines inoculum with natural $H$. glycines populations in the nonfumigated plots, or group 2, amendment of $F$. solani f. sp. glycines inoculum without $H$. glycines in the fumigated plots. Root necrosis and foliar SDS severity were high in group 1 and were low in group 2. In 2004, when the two pathogen populations were modified more drastically by amending them into nonfumigated or fumigated plots, varying levels of root necrosis were found in treatments that received at least one pathogen, but severe root necrosis was coupled with severe SDS foliar symptoms only in the co-inoculated treatments of Williams 82. We hypothesize that root necrosis caused by the infection of $F$. solani $\mathrm{f}$. sp. glycines reduced availability of feeding sites for $H$. glycines, thus decreasing nematode population densities. The notoriously scattered distribution of population densities of $H$. glycines may cause inconsistencies in results of field experiments to screen germplasm for resistance and in analyses of the interaction of both pathogens. On the other hand, F. solani f. sp. glycines not only can colonize, survive as thick-walled chlamydospores in, and be isolated from $H$. glycines cysts $(22,24,33)$, but also can affect population development of $H$. glycines (22). Cysts of $H$. schachtii, a close relative to $H$. glycines, have been shown to be effective transmitters for microorganisms (48), which can be beneficial in transferring nematode biocontrol organisms or detrimental by transmitting plant diseases.

In this study, both biotic (SCN) and abiotic (soil moisture) factors exacerbated the severity of SDS foliar symptoms. Effects of population levels of amended $F$. solani $\mathrm{f}$. sp. glycines on SDS development were minor in both fumigated and nonfumigated soil. Although soil suppressiveness probably was reduced in fumigated soil, as is the case for many soilborne pathogens (47), disease severity was not increased at any infestation level of F. solani f. sp. glycines after biocidal treatments in 2003. Moreover, the effects of amended $F$. solani $\mathrm{f}$. sp. glycines on SDS development were not significantly different from each other at different inoculum levels in the nonfumigated soil, but foliar SDS severity was increased by $\mathrm{H}$. glycines across all infestation levels. Effective management of SDS requires consideration of several factors, such as soil moisture level and the temperature at planting $(36,43)$, field managing practice (e.g., irrigation) $(24,32)$, the physical and chemical composition of soil $(38,40,41,45,46)$, the genetics of soybean resistance to SDS $(5,10)$, the pathological and physiological variability among different isolates of $F$. solani $\mathrm{f}$. sp. glycines $(17,31,43)$, and the interaction of $F$. solani $\mathrm{f}$. sp. glycines with $H$. glycines and other soil microorganisms $(20,24,32)$.

Understanding the interaction between $F$. solani f. sp. glycines and $H$. glycines is mandatory for management of SDS in fields with a history of $H$. glycines infestation. Management practices to reduce $H$. glycines populations are thought to delay the onset of SDS. Potentially, avoiding build-up of population densities of $F$. solani f. sp. glycines and $H$. glycines will be beneficial in reducing the risk for SDS (45). A strategy to accomplish the limitation of $H$. glycines build-up could include the use of $H$. glycinesresistant soybean cultivars. However, information is limited on the influence of $H$. glycines on SDS development in nematoderesistant soybean lines grown in $F$. solani f. sp. glycines-infested soil (15). Some $H$. glycines-resistant cultivars are more tolerant to SDS $(11,26,37)$, but some $H$. glycines-resistant soybean cultivars are particularly susceptible to SDS $(26,27)$. In general, SDS severity is greater on $H$. glycines-susceptible cultivars grown in $H$. glycines-infested fields $(11,36,37)$. For the future, it is imperative to determine $H$. glycines population densities when evaluating SDS tests in natural soils.

\section{ACKNOWLEDGMENTS}

This report is published with the Purdue University Agricultural Research Program Approval number 2005-17657. This research was made possible by support from the United Soybean Board, the North Central Soybean Research Program, and the Indiana Soybean Board. We appreciate the support of the Department of Agronomy and the Department of Botany and Plant Pathology, Purdue University. We thank S. T. Abney for providing fungal cultures of Fusarium solani f. sp. glycines; J. Santini for statistical help; G. T. Browne, L. D. Dunkle, S. B. Goodwin, and A. R. LeRoy for helpful input on the revisions of this report; R. Pillsbury, D. Sorrells, G. Kruger, M. Ngar, B. Banta, F. Heraux, L. Bugher, R. Hanslow, and the staff of the Agricultural Center of Research and Education and the Grounds Department of Purdue University for technical assistance; and C. Fuhrman for the provision of methyl bromide.

\section{LITERATURE CITED}

1. Adeniji, M. O., Edwards, D. I., Sinclair, J. B., and Malek, R. B. 1975. Interrelationship of Heterodera glycines and Phytophthora megasperma var. sojae in soybeans. Phytopathology 65:722-725.

2. Aoki, T., O’Donnell, K., Homma, Y., and Lattanzi, A. R. 2003. Suddendeath syndrome of soybean is caused by two morphologically and phylogenetically distinct species within the Fusarium solani species complex-F. virguliforme in North America and F. tucumaniae in South America. Mycologia 95:660-684.

3. Caswell, E. P., Thomason, I. J., and McKinney, H. E. 1985. Extraction of cysts and eggs of Heterodera schachtii from soil with an assessment of extraction efficiency. J. Nematol. 17:337-340.

4. Cattelan, A. J., Colombano, L. P., Betti, A. F. F., Cunha, F. E. I. D., and Ferracin, L. M. 2004. Soybean sudden death syndrome (Fusarium solani) controlled in greenhouse by inoculation with antagonistic bacteria. (Abstr.) Page 71 in: VII World Soybean Res. Conf. IV Int. Soybean Processing and Utilization Conf. III, Congresso Mundial de Soja (Brazilian Soybean Congress), Foz do lguassu, PR, Brazil.

5. Chang, S. J. C., Doubler, T. W., Kilo, V., Suttner, R., Klein, J., Schmidt, M. E., Gibson, P. T., and Lightfoot, D. A. 1996. Two additional loci underlying durable field resistance to soybean sudden death syndrome (SDS). Crop Sci. 36:1684-1688

6. Faghihi, J., and Ferris J. M. 2000. An efficient new device to release eggs from Heterodera glycines. J. Nematol. 32:411-413.

7. Faghihi, J., Vierling, R. A., Halbrendt, J. M., Ferris, V. R., and Ferris, J. M. 1995. Resistance genes in a 'Williams 82 ' $\times$ 'Hartwig' soybean cross to an inbred line of Heterodera glycines. J. Nematol. 27:418-421.

8. Fehr, W. R., Caviness, C. E., Burmood, D. T., and Pennington, J. S. 1971. Stage of development descriptions for soybeans, Glycine max (L.) Merrill. Crop Sci. 11:929-931.

9. Gray, L. E., and Achenbach, L. A. 1996. Severity of foliar symptoms and root and crown rot of soybean inoculated with various isolates and inoculum rates of Fusarium solani. Plant Dis. 80:1197-1199.

10. Hartman, G. L., Huang, Y. H., Nelson, R. L., and Noel, G. R. 1997. Germplasm evaluation of Glycine max for resistance to Fusarium solani, the causal organism of sudden death syndrome. Plant Dis. 81:515-518. 
11. Hershman, D. E., Hendrix, J. W., Stuckey, R. E., and Bachi, P. R. 1990. Influence of planting date and cultivar on soybean sudden death syndrome in Kentucky. Plant Dis. 74:761-766.

12. Howard, D. D., Chambers, A. Y., and Newman, M. A. 1999. Reducing sudden death syndrome in soybean by amending the soil with chloride. Commun. Soil Sci. Plant Anal. 30:545-555.

13. Hussey, R. S., and McGuire, J. M. 1987. Interaction with other organisms. Pages 293-328 in: Principles and Practice of Nematode Control in Crops. R. H. Brown, and B. R. Kerry, eds. Academic Press, Sydney, Australia.

14. Iqbal, M. J., Yaegashi, S., Njiti, V. N., Ahsan, R., Cryder, K. L., and Lightfoot, D. A. 2002. Resistance locus pyramids alter transcript abundance in soybean roots inoculated with Fusarium solani f. sp. glycines. Mol. Gen. Genet. 268:407-417.

15. Jackson, T. A., Niblack, T. L., and Smith, G. S. 2002. Effects of Heterodera glycines population levels on Fusarium solani f. sp. glycines colonization of near-isogenic soybean lines differing in resistance to each pathogen. (Abstr.) Phytopathology 92(suppl.):S38.

16. Jin, H., Hartman, G. L., Nickell, C. D., and Widholm, J. M. 1996. Characterization and purification of a phytotoxin produced by Fusarium solani, the causal agent of soybean sudden death syndrome. Phytopathology $86: 277-282$.

17. Killeberew, J. F., Roy, K. W., Lawrence, G. W., McLean, K. S., and Hodges, H. H. 1988. Greenhouse and field evaluation of Fusarium solani pathogenicity to soybean seedlings. Plant Dis. 72:1067-1070.

18. Lawrence, G. W., Roy, K. W., and McLean, K. S. 1988. Soybean cyst nematode associations with sudden death syndrome of soybeans. (Abstr.) Phytopathology 78:1514.

19. Luo, Y., Myers, O., Lightfoot, D. A., and Schmidt, M. E. 1999. Root colonization of soybean cultivars in the field by Fusarium solani f. sp. glycines. Plant Dis. 83:1155-1159.

20. McLean, K. S., and Lawrence, G. W. 1993. Interrelationship of Heterodera glycines and Fusarium solani in sudden death syndrome of soybean. J. Nematol. 25:434-439.

21. McLean, K. S., and Lawrence, G. W. 1993. Localized influence of Heterodera glycines on sudden death syndrome of soybean. J. Nematol. 25:674-678.

22. McLean, K. S., and Lawrence, G. W. 1995. Development of Heterodera glycines as affected by Fusarium solani, the causal agent of sudden death syndrome of soybean. J. Nematol. 27:70-77.

23. Melgar, J., and Roy, K. W. 1994. Soybean sudden death syndrome: Cultivar reactions to inoculation in a controlled environment and host range and virulence of causal agent. Plant Dis. 78:265-268.

24. Melgar, J., Roy, K. W., and Abney, T. S. 1994. Sudden death syndrome of soybean, etiology, symptomatology, and effects of irrigation and Heterodera glycines on incidence and severity under field conditions. Can. J. Bot. 72:1647-1653.

25. Njiti, V. N., Meksem, K., Iqbal, M. J., Johnson, J. E., Kassem, M. A., Zobrist, K. F., Kilo, V. Y., and Lightfoot, D. A. 2002. Common loci underlie field resistance to soybean sudden death syndrome in Forrest, Pyramid, Essex, and Douglas. Theor. Appl. Genet. 104:294-300.

26. Njiti, V. N., Schenaut, M. A., Suttner, R. J., Schmidt, M. E., and Gibson, P. T. 1996. Soybean response to sudden death syndrome: Inheritance influenced by cyst nematode resistance in Pyramid $\times$ Douglas progenies. Crop Sci. 36:1165-1170.

27. Njiti, V. N., Suttner, R. J., Gray, L. E., Gibson, P. T., and Lightfoot, D. A. 1997. Rate-reducing resistance to Fusarium solani f. sp. phaseoli underlies field resistance to soybean sudden death syndrome. Crop Sci. 37:132-138.

28. Ortiz-Ribbing, L. M., and Eastburn, D. M. 2004. Soybean root systems and sudden death syndrome severity: Taproot and lateral root infection. Plant Dis. 88:1011-1016.

29. Ross, J. P. 1965. Predisposition of soybeans to Fusarium wilt by Heterodera glycines and Meloidogyne incognita. Phytopathology 55:361-364.

30. Roy, K. W. 1997. Fusarium solani on soybean roots: Nomenclature of the causal agent of sudden death syndrome and identity and relevance of $F$. solani form B. Plant Dis. 81:259-266.

31. Roy, K. W., Hershman, D. E., Rupe, J. C., and Abney, T. S. 1997. Sudden death syndrome of soybean. Plant Dis. 81:1100-1111.

32. Roy, K. W., Lawrence, G. W., Hodges, H. H., McLean, K. S., and Killebrew, J. F. 1989. Sudden death syndrome of soybean: Fusarium solani as incitant and relation of Heterodera glycines to disease severity. Phytopathology 79:191-197.
33. Roy, K. W., Patel, M. V., and Baird, R. E. 2000. Colonization of Heterodera glycines cysts by Fusarium solani form A, the cause of sudden death syndrome, and other fusaria in soybean fields in the Midwestern and southern United States. Phytoprotection 81:57-67.

34. Rupe, J. C. 1989. Frequency and pathogenicity of Fusarium solani recovered from soybeans with sudden death syndrome. Plant Dis. 73:581584.

35. Rupe, J. C., Becton, C. M., Williams, K. J., and Yount, P. 1996. Isolation, identification and evaluation of fungi for the control of sudden death syndrome of soybean. Can. J. Plant Pathol. 18:1-6.

36. Rupe, J. C., and Gbur, E. E., Jr. 1995. Effect of plant age, maturity group, and the environment on disease progress of sudden death syndrome of soybean. Plant Dis. 79:139-143.

37. Rupe, J. C., Gbur, E. E., Jr., and Marx, D. M. 1991. Cultivar responses to sudden death syndrome of soybean. Plant Dis. 75:47-50.

38. Rupe, J. C., Robbins, R. T., Becton, C. M., Sabbe, W. A., and Gbur, E. E., Jr. 1999. Vertical and temporal distribution of Fusarium solani and Heterodera glycines in fields with sudden death syndrome of soybean. Soil Biol. Biochem. 31:245-251.

39. Rupe, J. C., Robbins, R. T., and Gbur, E. E., Jr. 1997. Effect of crop rotation on soil population densities of Fusarium solani and Heterodera glycines and on the development of sudden death syndrome of soybean. Crop Prot. 16:575-580.

40. Rupe, J. C., Sabbe, W. E., Robbins, R. T., and Gbur, E. E., Jr. 1993. Soil and plant factors associated with sudden death syndrome of soybean. J. Prod. Agric. 6:218-221.

41. Sanogo, S., and Yang, X. B. 2001. Relation of sand content, pH, and potassium and phosphorus nutrition to the development of sudden death syndrome in soybean. Can. J. Plant Pathol. 23:174-180.

42. Scandiani, M., Fulgueira, C., Amigot, S., Bottai, H., Pioli, P., Giorda, L., and Ruberti, D. 2004. In vitro antagonistic activity of Streptomyces strains against soybean sudden-death syndrome isolates. (Abstr.) Page 71 in: VII World Soybean Res. Conf. IV Int. Soybean Processing and Utilization Conf. III, Congresso Mundial de Soja (Brazilian Soybean Congress), Foz do lguassu, PR, Brazil.

43. Scherm, H., and Yang, X. B. 1996. Development of sudden death syndrome of soybean in relation to soil temperature and soil water matric potential. Phytopathology 86:642-649.

44. Scherm, H., and Yang, X. B. 1999. Risk assessment for sudden death syndrome of soybean in the north-central United States. Agric. Syst. 59:301-310.

45. Scherm, H., Yang, X. B., and Lundeen, P. 1998. Soil variables associated with sudden death syndrome in soybean fields in Iowa. Plant Dis. 82:1152-1157.

46. Vick, C. M., Chong, S. K., Bond, J. P., and Russin, J. S. 2001. Soybean sudden death syndrome and the soil physical environment: A two-year study. (Abstr.) Phytopathology 91(suppl.):S92.

47. Weller, D. M., Raaijmaker, J. M., McSpadden Gardener, B. B., and Thomashow, L. S. 2002. Microbial populations responsible for specific soil suppressivness to plant pathogens. Annu. Rev. Phytopathol. 40:309348.

48. Westphal, A., and Becker, J. O. 2001. Components of soil suppressiveness against Heterodera schachtii. Soil Biol. Biochem. 33:9-16.

49. Workneh, F., Tylka, G. L., Yang, X. B., and Ferris, J. M. 1999. Regional assessment of soybean brown stem rot, Phytophthora sojae and Heterodera glycines using area-frame sampling: Prevalence and effects of tillage. Phytopathology 89:204-211.

50. Wrather, J. A., Koenning, S. R., and Anderson, T. R. 2003. Effects of diseases on soybean yields in the United States and Ontario (1999-2002). Plant Health Progress. Online DOI:10.1094/PHP-2003-0325-01-RV.

51. Xing, L. J., Santini, J. B., and Westphal, A. 2004. Soybean root necrosis in response to infestation levels of Fusarium solani f. sp. glycines. (Abstr.) Phytopathology 94(suppl.):S162.

52. Xing, L. J., and Westphal, A. 2004. Effect of soybean cyst nematode, soil moisture and infestation level on sudden death syndrome of soybean. (Abstr.) Phytopathology 94(suppl.):S112.

53. Xing, L., and Westphal, A. 2005. Development of sudden death syndrome in two soybean lines in field microplots infested with Fusarium solani f. sp. glycines and Heterodera glycines. (Abstr.) J. Nematol. 37:403-404.

54. Xing, L., and Westphal, A. 2005. In vitro test for inhibition of Fusarium solani f. sp. glycines with biocontrol agents. (Abstr.) Phytopathology 95(suppl.):S114 